\title{
Pratt, Mary Louise (2010), Ojos imperiales. Literatura de viajes y transculturación, México: Fondo de Cultura Económica.
}

$\amalg$ n este libro, editado por el Fondo de Cultura Económica, encontramos nueve capítulos distribuidos en tres apartados, los cuales están acompañados de 37 ilustraciones que hacen amena y explícita la lectura. Cuenta con tres fotografías y una copia de la carta escrita por un viajero-explorador del África, el Dr. Livingstone. ${ }^{1}$

Con este texto, Mary Louise Pratt hace visibles las amarras que mantienen al conocimiento, la historia y las relaciones humanas, ancladas al oleaje incesante de un orden imperial. En otros términos, estamos frente a una parte significativa de lo que es la literatura de viajes y la manera como se ha configurado. Para ello la autora nos presenta una visión del mundo, una manera de ser, un discurso inserto en las líneas de la literatura de viajes cuyo inicio está señalado a mediados del siglo XVIII. Pratt insiste en que la presencia, o bien la permanencia de un sistema, es decir, lo que hace posible que las convenciones, tropos, relaciones imperiales expresadas en este género, atraviesen vidas, tiempos y espacios distantes entre sí (aparentemente), se debe a las formas en que éstas han mutado.

En relación con las prácticas que se prolongan en el tiempo, Octavio Ianni... en su obra Enigmas de la modernidad, ha escrito que el viaje atraviesa la historia de los pueblos en forma de metáfora o de realidad, que todas las formas de sociedad, incluyendo tribus, clanes, naciones y nacionalidades, colonias e imperios, trabajan y vuelven a trabajar la cuestión del viaje, ya sea como modo de descubrir al 'otro', o como modo de descubrir el 'yo'. Desde esta perspectiva se desprende otra práctica, la de trasmitir, narrar la experiencia, describir y en última instancia escribir. ${ }^{2}$ En este sentido, los que escriben no son solamente viajeros, también lo hacen los "viajados", ambas plumas compartiendo los "ojos imperiales". Europa es el centro y todo lo demás es "su periferia", los territorios lejanos, y sus pobladores "alejados" cumplen funciones ordenadoras para el interior del Omperio. De esta manera, la geografía "de lo malo y lo bueno" estaba trazada, ya se podía saber de dónde venían las enfermedades, las costumbres y la gente extraña. Al abordar el tema, Olga Sabido, en su escrito "El extraño" - incluido en la obra Los rostros del otro, editado por Emma León- refiere que lo extraño y la experiencia de tal acontecimiento, la extrañeza, son una constante en la humanidad, aunque el sentido y las reacciones frente a ella hayan variado a lo largo de la historia.

La otra parte del título está en la perspectiva de viajeros y "viajados" que hacen uso del instrumento para contar la historia a contrapelo, en el que la apuesta es la descolonización. En los términos planteados por 
Walter Mignolo, ${ }^{3}$ estaríamos en una contribución al “desprendimiento epistémico", el cual está constituido por un pensamiento fronterizo, que proviene de pensar la experiencia de sujetos fracturados por la colonialidad desde categorías ajenas al lenguaje colonizador.

La investigación realizada por Pratt contribuye también a desentrañar las conexiones del concepto polifónico de "viaje", es decir, contiene en términos coloquiales "piezas del rompecabezas", útiles para entender la conceptualización que hace Clifford, en Itinerarios transculturales, quien ha sugerido utilizar el término "viaje" como traducción por estar conectado con la clase, el género y cierto carácter literario. De la misma manera, Todorov advierte que el "viaje" como práctica ha estado asociado a la raza, el género o la condición económica de quien lo realiza. Los primeros "viajeros" fueron religiosos, escritores, exploradores, comerciantes, que comenzaron a recorrer lugares distantes.

Los conceptos que Mary Louise Pratt establece en su pesquisa son zona de contacto, anticonquista, autoetnografía o expresión autoetnográfica. Con el término zona de contacto, la autora se refiere al espacio de los encuentros coloniales, en el que personas separadas por geografía e historia tienen contacto entre sí y establecen relaciones sostenidas, en las que prevalecen la coerción, la inequidad y el correspondiente conflicto. La anticonquista en esta obra alude a las estrategias que miembros de la burguesía europea despliegan para presentar una cara inocente, y al mismo tiempo afirmar su hegemonía y superioridad. El término se niega a sí mismo y es utilizado para ilustrar de manera inequívoca que la mirada pasiva desplegada por el imperialista paseante, sin perturbar la vida de los pueblos que atraviesa con pies y ojos, lleva consigo, de una u otra manera, una pretensión de apropiación. La autoetnografía o expresión autoetnográfica, se refiere a la manera en que los conquistados responden o dialogan con las representaciones que los conquistadores hacen de los primeros y que están construidas con los mismos términos y códigos del colonizador. Un ejemplo temprano es el escrito de Guamán Poma de Ayala. En dicho documento de 1,200 páginas hay una apropiación de la forma literaria para representar la historia y las costumbres de los pueblos incaicos, en su Nueva crónica enviada al rey Felipe III de España.

Como advertíamos al principio, los tres apartados que conforman el libro de Mary Louise Pratt guardan conexiones con el concepto de viaje que utiliza Clifford Cada uno de los capítulos nos muestra los hilos temáticos que conforman la madeja, sin posibilidades de desenredarla, pero con amplias expectativas de propiciar la comprensión y, nos dice la autora, “... pretende debilitar el control del imperialismo sobre la imaginación y el conocimiento, y de generar zonas despejadas para instalar mejores formas de vida y conocimiento del mundo."

La primera parte del libro está propuesta en la articulación de acontecimientos que alteran directamente la experiencia de viaje. Por una parte, tenemos el Sistema de naturaleza de Linneo publicado en $1735 \mathrm{y}$, por el otro, las exploraciones al interior de los continentes. Con ellos, Pratt ilustra su propio supuesto metodológico, “...las transiciones históricas importantes alteran la manera en que la gente escribe porque alteran sus experiencias y, con ello, también la manera de imaginar, sentir y pensar el mundo en el que viven".

De esta idea, renombrar, redescubrir, catalogar a la naturaleza, no pasará mucho tiempo hasta que aparezcan los primeros "viajes científicos", desatando toda una industria avocada al desarrollo de la medición, la conservación y el traslado. Los descubrimientos, las conquistas y las circunnavegaciones, permitieron rediseñar el mapa del mundo, localizando continentes, islas, archipiélagos, montañas, planicies, ríos, lagos, mares y océanos, así como fauna, climas y nichos ecológicos, al mismo tiempo que tribus, clanes, razas, etnias, religiones, lenguas, naciones, nacionalidades, colonias, imperios culturas y civilizaciones. Otro punto interesante se encuentra en la transformación 
ética de esta manera de apropiación, presentada como buena e inocente. Establece, pues, una distancia entre la conquista y la conversión religiosa, con sus signos imperiales de esclavitud, apropiación de territorios, destrucción. Con la idea de ver/presentar utópica e inocentemente la autoridad europea global, Pratt la nombra como "la anticonquista", la cual tiene implicaciones en la moral europea en términos de reciprocidad capitalista. Asimismo, están planteadas las relaciones mediadas por el "amor" entre conquistadores y conquistados en busca de una armonía cultural a través del romance.

El segundo apartado está centrado en un acontecimiento que tiene fuertes implicaciones en las maneras de imaginar el mundo, y que se gesta desde finales del siglo XVIII: los movimientos de independencia en la mayoría de las colonias americanas. Sin duda alguna, éstos marcaron un cambio sustancial en las formas de experimentar los viajes. Uno de los primeros en percibirlo fue el prusiano Alexander Von Humboldt, quien llevó a cabo su periplo con pretensiones de capturar las fuerzas invisibles del nuevo mundo. A su paso por México escribió el Ensayo político sobre el reinado de la Nueva España. ${ }^{4}$ En este trabajo, la ideología de Humboldt se inclina más hacia la postura ambientalista que a considerar el grado de avance cultural de México y América del Sur 5 . Para finales del siglo XIX, estas visiones habían regresado a América en forma de literatura, alimentando posturas jerárquicas. Como señala Beatriz Urías en su libro Teoría sobre las razas, el discurso en torno a la idea de que las razas estaban jerarquizadas en función de un estado de atraso o de avance que tomaba como referencia la civilización occidental, se articuló a través de tres grandes ejes temáticos: lo fisiológico, lo cultural y lo lingüístico. De alguna manera, los escritos de Humboldt recrearon expectativas en los viajeros ingleses que le sucedieron. Esta vez la anticonquista se basaba en el establecimiento de contactos y contratos con las élites criollas. Nos encontramos en plena reinvención de América, la que da cuenta de una sociedad americana descuidada y atrasada, con necesidad de ser explotada racionalmente. En esta tarea también se incluyen "otros ojos", los de las mujeres-viajeras-escritoras que recorren los asilos, mercados, cárceles, orfanatos, conventos, a quienes Pratt denomina "exploratrices sociales". En las experiencias de viaje realizadas por mujeres se empleaban formas ocasionales, por ejemplo las cartas de lady Montagu en Turquía y Mary Wollstonecraft ${ }^{6}$ en Escandinavia. Después de los movimientos de independencia, la reinvención de América pasó a manos de los criollos. La tarea era la conformación de las nacientes republicas y la construcción de la nación.

En el último de los tres apartados, Mary Louise Pratt nos señala el viaje como generador de acontecimientos que cambian las formas de vida en todo el mundo. La carrera por el descubrimiento donde se encuentran enmarcados hace emerger empresas nacionales, el prestigio de llegar primero, renombrar. Al respecto Pratt dice: "el descubrimiento consistía en un gesto que convertía los conocimientos locales en conocimientos europeos nacionales y continentales". Para ello, se presenta un acto que, para la cultura europea, estaba centrado en la experiencia pasiva de mirar. De esta forma, lo que se asigna en cuanto a los valores, significados, espacios o acomodos, pertenecen al que ve. Cabe señalar que todas estas experiencias de viaje hasta ahora señaladas están planteadas en términos de circuitos coloniales, neocoloniales o poscoloniales, es decir, llevan inscrito el regreso en forma de supervivencia, heroica, científica, literaria, emancipadora. Para la introducción del capítulo IX, Pratt resalta dos acontecimientos que explican las transformaciones, no de la experiencia, sino de quien experimenta el viaje, que nos invitan a pensar en términos de una nueva fase imperial: la caída de la Unión Soviética y la revolución en las formas de comunicación.

Mary Louise Pratt nos enseña con este libro que muchas de las vueltas y reveses con que está tejida 
nuestra realidad tienen un comienzo lejano. Es una labor de ir "destejiendo fino", en la que nos devela la serie de hilos entrelazados que, en conjunto, conforman el discurso occidental —europeo- De este modo, el imperio estableció lugares, el centro y su periferia, a la vez que hacía participe a sus locales de expediciones —orden, jerarquía- y clasificación —nombre-. De la lectura surge otra forma de leer la historia contenida en los relatos de viajes, sin dejar de tener en cuenta que es un instrumento de su tiempo con la tarea de dar cuenta de los cambios y los descubrimientos recientes de una naturaleza ominosa. Es decir, la literatura de viajes acercaba, alejaba, hacia ver de manera familiar territorios, dibujaba lo extraño y lo plasmaba en imaginarios compartidos. Hoy son otros los medios que dan cuenta de relatos dramáticos. Todos los días en la prensa del mundo se escenifica el nuevo orden planetario, un orden imperial que ha mutado y creado sus propios sujetos, con sus jerarquías y sus relaciones características, estableciendo su propia política de la mirada.

Algunas tareas pendientes podrían consistir en la necesidad de trazar la cartografía del planeta reconfigurado nuevamente por las potencias movilizadoras de la tecnología, la necesidad y el imperio; tener en cuenta que la permanencia como ordenamiento social de la humanidad, junto con la movilidad, ya no son los únicos criterios para definir la ciudadanía y la pertenencia; poner atención en los estudios que contemplan como tema central el viaje para privilegiar la mirada en las relaciones interrumpidas, las identidades, los "costos", las experiencias de los viajeros, el trabajo en otros sitios para los individuos y las comunidades. Asimismo, el lector podrá hacer sus propios cuestionamientos a la autora cuando sostiene que el adentro y el afuera no corresponden a la permanencia y la movilidad, ni marcan la intensidad de las relaciones. Es decir, lo cercano y lo lejano son ya una elección.

\section{Notas}

${ }^{1}$ El nombre del Dr. Livingstone es utilizado para ejemplificar la mutación-permanencia de un personaje-viajero-explorador del siglo XVIII, el cual aparece de diferentes formas referido en el propio entorno de Pratt.

2 Las experiencias de viajes no siempre han sido plasmadas en escritos por los mismos viajeros, aun cuando los mismos sean reconocidos por sus periplos. Por ejemplo, Marco Polo relata sus viajes al escribano cuando está en prisión; Ibn Battuta narra al amanuense 30 años después de su recorrido.

3 La propuesta del "desprendimiento epistémico" es tratada en el artículo "La opción de-colonial: desprendimiento y apertura. Un manifiesto y un caso", en Tabula Rasa, Bogotá, enero-junio 2008, núm. 8, pp. 243-281.

${ }^{4}$ De acuerdo con Beatriz Urias, Humboldt profesaba un liberalismo opuesto a la esclavitud. Apoyó la Revolución francesa y las independencias de América y nunca imaginó que posteriormente a este escrito se desataría una oleada franco-mexicana para medir cráneos (antropometría) y determinar la teoría de la inferioridad de las razas.

5 Para Urias, de la etnología se desprenden dos corrientes: la monogenética, acerca del origen único de la humanidad, recogía la representación bíblica y atribuía las razas al medio en que los descendientes de Adán y Eva habían habitado. La poligenética, el principio básico de diferenciación de las razas fue el lenguaje, y el medio habría determinado los rasgos físicos y culturales.

${ }^{6}$ Esta escritora es la autora de Frankenstein o el moderno Prometeo, obra basada en las cartas y diario de Robert Walton desde un viaje en barco.

León Felipe Solar-Fonseca CESMECA-UNICACH 